\title{
Hydro-Adsorption Study by Dynamic Laser Speckle of Natural Zeolite for Adsorbent and Fertilizer Applications
}

\author{
Ruth Dary Mojica-Sepulveda', Luís Joaquín Mendoza-Herrera',3, María Florencia Agosto ${ }^{4}$, \\ Eduardo Grumel2,3, Delia Beatriz Soria1, Carmen Inés Cabello3,5,6*, Marcelo Trivi²,3,6 \\ ${ }^{1}$ Centro de Química Inorgánica (CEQUINOR), [Universidad Nacional de La Plata (UNLP)-Consejo Nacional de Ciencia y Tecnología \\ (CONICET)-Centro Científico y Tecnológico La Plata (CCT)], La Plata, Argentina \\ ${ }^{2}$ Centro de Investigaciones Opticas (CIOP), [Consejo Nacional de Ciencia y Tecnología (CONICET)-Centro Científico y Tecnológico La \\ Plata (CCT)-Universidad Nacional de La Plata (UNLP)-Comisión de Investigaciones Científicas y Técnicas de la Provincia de Buenos \\ Aires, (CICPBA)], La Plata, Argentina \\ ${ }^{3}$ Facultad de Ingeniería, Universidad Nacional de La Plata (UNLP), Buenos Aires, Argentina \\ ${ }^{4}$ Universidad Nacional de Río Negro, Viedma, Argentina \\ ${ }^{5}$ Centro de Investigación y Desarrollo en Ciencias Aplicadas (CINDECA), [Universidad Nacional de La Plata (UNLP)-Consejo Nacional \\ de Ciencia y Tecnología (CONICET)-Centro Científico y Tecnológico La Plata (CCT)], La Plata, Argentina \\ ${ }^{6}$ Comisión de Investigaciones Científicas y Técnicas de la Provincia de Buenos Aires (CICPBA), La Plata, Argentina \\ Email: *ccabello@quimica.unlp.edu.ar
}

How to cite this paper: Mojica-Sepulveda, R.D., Mendoza-Herrera, L.J., Agosto, M.F., Grumel, E., Soria, D.B., Cabello, C.I. and Trivi, M. (2016) Hydro-Adsorption Study by Dynamic Laser Speckle of Natural Zeolite for Adsorbent and Fertilizer Applications. Advances in Chemical Engineering and Science, 6, 570-583.

http://dx.doi.org/10.4236/aces.2016.65049

Received: November 4, 2016

Accepted: December 25, 2016

Published: December 29, 2016

Copyright $\odot 2016$ by authors and Scientific Research Publishing Inc. This work is licensed under the Creative Commons Attribution International License (CC BY 4.0). http://creativecommons.org/licenses/by/4.0/ c) (i) Open Access

\begin{abstract}
The dynamic behavior caused by hydro-adsorption process of materials based on a rich mineral clinoptilolite together with their acidic, basic and calcinated forms has been studied by the dynamic laser speckle (DLS) technique. We propose a modified Peleg's equation to improve fitting of DLS data. Textural (BET), structural (XRD) and spectroscopic (FTIR) properties were also studied and compared. We demonstrated that DLS was the most sensitive, simple and inexpensive method for comparing the performance of adsorptive materials with slightly modified surfaces. It also allowed the correlation with physicochemical properties.
\end{abstract}

\section{Keywords}

Natural Zeolites, Adsorbents, Hydro-Adsorption, Laser, Speckle

\section{Introduction}

The minerals based on aluminosilicates such as clays (kaolinite, montmorillonite) and zeolites (clinoptilolite) are abundant and inexpensive [1]. Zeolites present a lot of peculiar characteristics, one of them is the property of adsorbents for removing bacteria and 
pollutants [2] [3] [4] [5]. Clinoptilolite is a natural, non-toxic zeolite with strong adsorptive and ion-exchange capacity [5] [6]. Its structure is formed with a $3 \mathrm{D}$ framework, built up by tetrahedral $\mathrm{TO}_{4}\left(\mathrm{~T}=\mathrm{Al}^{3+}, \mathrm{Si}^{+4}\right)$, sharing all their vertexes linking together and forming different rings of 6, 8, 10 and 12 member [5] [6]. The parameter framework density, FD (number of the T atoms per $1000 \AA^{3}$ of volume) is useful for distinguish Zeolites from other dense tecto-silicates, ranging between 12 and 20 for Zeolites [2]. The treatment of the zeolite surface with concentrated acids or bases also modifies their hygroscopic properties [5] [6]. It is well known that the presence of hydrogen bonding interactions, and electrostatic forces of attraction on the surface of zeolites modified with anionic and/or cationic species has a significant effect on the process of microorganism elimination [3] [4]. Also, the pronounced selectivity of clinoptilolite for large cations, such as ammonium and potassium, has also been used in the preparation of chemical fertilizers that improve the nutrient-retention ability of the soils [7]. In our previous studies, this geomaterial produced an optimal degree of exchange with ammonium $\mathrm{NH}_{4}{ }^{+}$( $\sim 90 \%$ of the theoretical CEC) and showed a good performance as a slow nitrogen release fertilizer applied in crops grown with two types of Argentine soil. These results revealed the potential of ammonium clinoptilolite system in sustainable agricultural production [8].

Natural and modified zeolites and their applications have been widely studied, so determination of textural and structural properties has been of great interest. Usually, the hygroscopic properties of the zeolites can be characterized by the well-known TG-DTA, $\mathrm{XRD}$, FTIR and BET methods [3] [4] [5]. Recently dynamic laser speckle technique (DLS) has been used for estimate the hygroscopic capacity in commercial silica $\left(\mathrm{SiO}_{2}\right)$ and clays with different textural properties. The DLS represents a technologically advanced and methodologically accurate method based on the optical random interferometric phenomenon named "speckle", produced when a laser light illuminates a rough surface [9] [10]. This effect shows the temporal evolution of materials speckle patterns during water adsorption and a correlation of the speckle activity with the textural properties. This analysis can be considered as an alternative method to study different porous materials of interest such as absorbents or catalysts supports [11] [12].

The present work addresses the implementation of dynamic laser speckle technique to the hydro-adsorption analysis of natural zeolite, clinoptilolite, and their acidic, basic and thermally treated forms. This technique can be very useful to estimate its hygroscopic capacity.

In this paper, experimental DLS data were fitted using the Hawkes and Flink [13]; Azuara et al. [14] [15] [16] and Peleg [17]-[23] theoretical adsorption methods. These fitting were improved modifying the Peleg's equation.

In view of the versatile importance of the DLS technique, we here report its application together with physicochemical analysis such as XRD, FTIR and BET method.

\section{Materials and Methods}

The natural granular clinoptilolite zeolite used in this study was obtained from La Rioja 
(northwestern province of Argentine). A sample with the chemical composition given in Table 1 was selected. Data were obtained by Inductively Coupled Plasma-Atomic Emission Spectroscopy (ICP-AES) by $\mathrm{LiBO}_{2} / \mathrm{Li}_{2} \mathrm{~B}_{4} \mathrm{O}_{7}$ fusion (ACME Company, Canada) [24] [25].

The natural zeolite was ground manually in order to obtain a granular form as a solid powder, then $1 \mathrm{~g}$ of the solid powder was treated with $10 \mathrm{~mL}$ of ammonium hydroxide (1 M) solution for basic modification and $10 \mathrm{~mL}$ of concentrated nitric acid (1 M) for the acid one. Both samples were stirred during 12 hours and heated at $70^{\circ} \mathrm{C}$.

Solid samples were separated from the solution by filtration and washed with distilled water several times till the effluent became neutral to $\mathrm{pH}$ paper.

On the other hand, two samples of $1 \mathrm{~g}$ of original zeolite were thermally treated at $250^{\circ} \mathrm{C}$ and $500^{\circ} \mathrm{C}$ for $2 \mathrm{~h}$ in air. The zeolites ( $\mathrm{Z}$, in what follows) natural and the zeolites modified: $\mathrm{Z}-\mathrm{H}^{+}$(acid form), $\mathrm{Z}-\mathrm{NH}_{4}{ }^{+}$(basic form); Z-250 and Z-500 (zeolites heated at different temperatures). Characterization of original and treated zeolites was performed by Electronic microscopy using a Philips SEM 505 combined with semiquantitative analysis by energy dispersive X-ray analysis (EDS) by an analyzer EDAX 9100. Diagrams of X-ray diffraction powders (XRD) were registered using a Philips PW 1714 with a $\mathrm{CuK} \alpha$ radiation and $\mathrm{Ni}$ filter from $2 \theta=5^{\circ}$ to $60^{\circ}$. Infrared FTIR Spectra were obtained by a Equinox 50 FTIR equipment, from 4000 to $400 \mathrm{~cm}^{-1}$ wave-numbers. Surface areas and porosity of samples were determined by physical $\mathrm{N}_{2}$ adsorption at $77 \mathrm{~K}$ (BET method [26]) using a Micromeritics apparatus ASAP 2010.

\subsection{Dynamic Laser Speckle (DLS) Technique}

A typical granular interference pattern named "speckle" is observed [9] [10] when a coherent beam coming from a laser illuminates a rough object. Besides, a laser light scattered from diffuse objects produces a similar pattern.

If this surface presents some type of local movement, then the intensity pattern evolves in time. This phenomenon, known as "dynamic laser speckle" (DLS), can be observed in biological samples [9] and in non-biological industrial processes, including the drying of paint, corrosion and heat exchange [10]. This effect takes place when the sample changes its surface properties due to the movement of the scattering centers; changes in the optical path due to variations of refractive index; configuration changes or combination of these situations [10]. The temporary evolution of the speckle patterns is correlated with the "activity" of the sample and may provide an interesting tool to characterize the parameters involved in these processes. In this case, the speckle patterns showed a high activity for the initial hydro-adsorption process and it is minimal when this process is complete.

Table 1. Chemical analysis of bare clinoptilolite by ICP-AES analysis. (Majority elements (as \% oxides)).

\begin{tabular}{cccccccccccc}
\hline $\mathrm{SiO}_{2}$ & $\mathrm{TiO}_{2}$ & $\mathrm{Al}_{2} \mathrm{O}_{3}$ & $\mathrm{Fe}_{2} \mathrm{O}_{3}$ & $\mathrm{FeO}$ & $\mathrm{MnO}$ & $\mathrm{MgO}$ & $\mathrm{CaO}$ & $\mathrm{Na}_{2} \mathrm{O}$ & $\mathrm{K}_{2} \mathrm{O}$ & $\mathrm{P}_{2} \mathrm{O}_{5}$ & $\mathrm{LOI}$ \\
\hline 61.8 & 0.31 & 13.21 & 1.51 & 0.00 & 0.01 & 0.89 & 3.73 & 1.94 & 1.34 & 0.06 & 14.08 \\
\hline
\end{tabular}

LOI: Loss on ignition. 
We propose a DLS method to characterize the water adsorption of the zeolite. We employed a $10 \mathrm{~mW}$ He-Ne laser to illuminate the samples. Dynamic speckle pattern were recorded with a CCD camera connected to a frame grabber to digitize the images as shown in Figure 1. During this process, $30 \mathrm{mg}$ of each zeolite sample were impregnate with $10 \mu \mathrm{l}$ distilled water. The total experiment was carried out at $19^{\circ} \mathrm{C}$ and $60 \%$ of humidity.

We used Oulamara et al. method [9] to show the temporal evolution of speckle. In our case, 320 successive images (25 frames per second) of dynamic speckle were recorded for each state of the adsorption process and selecting a column of them. With these columns, a pseudo-image of $320 \times 240$ was constructed and so-called Temporary History Speckle Patterns (THSP).

The speckle activity of the sample changes their intensity in the horizontal direction. Therefore, when a phenomenon shows low activity, time variations of the speckle pattern are slow and the THSP shows elongated shape. When the phenomenon is very active, the THSP resembles an ordinary speckle pattern. See Figure 2.

The moment of inertia of the co-occurrence matrix method [10] was used for a quantitative estimate of THSP. The moment of inertia is defined by:

$$
I=\sum_{i} \sum_{j} M_{i j}(i-j)^{2}
$$

where $M_{i j}$ represents the number of occurrences of the gray-level $i$ followed in the time direction by gray-level $j$ in the THSP image, which forms an intermediate matrix called a co-occurrence matrix.

In our case, the initial value of $I$ decreases as the water is adsorbed by the zeolite surface until reaching the steady state, thus it is directly related to the adsorbed water amount.

\subsection{Adsorption Theoretical Models}

For modeling the amount of adsorbed water on solids vs. time, different models have been reported [13]-[23].

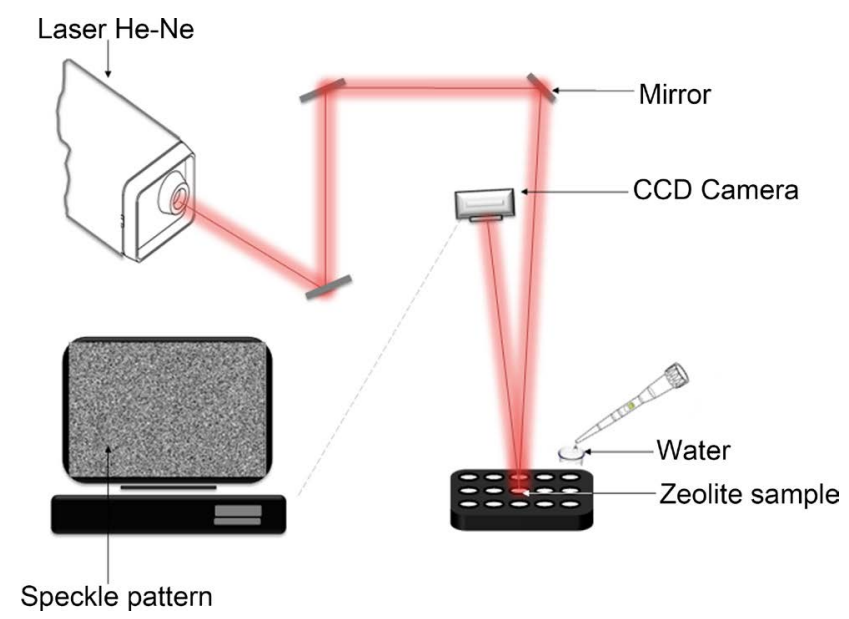

Figure 1. Experimental set-up for dynamic speckle technique. 


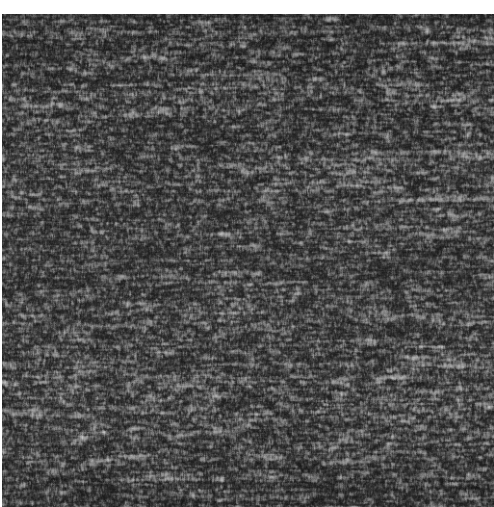

(a)

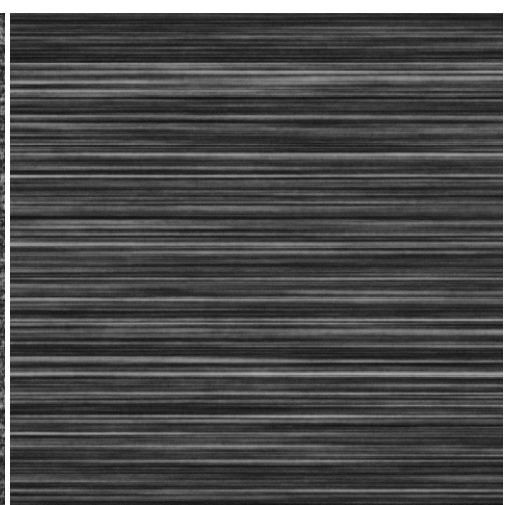

(b)

Figure 2. Temporal History of Speckle Pattern (THSP), (a) high activity (initial hydro-adsorption process), (b) low activity (process is complete).

Hawkes and Flink [13] studied the kinetics of water loss and solute uptake for solutions of differing composition and concentration. Several of the osmotically pre-concentrated freeze dried apple slices for organoleptic acceptability were evaluated using the following equation:

$$
N S C=K t^{0.5}
$$

where NSC is the normalized solids, $K$ is defined as the mass transfer coefficient and $t$ is the time.

Azuara et al. [14] [15] [16] developed a two-parameter equation from mass balance considerations. This equation was used to predict the kinetics of osmotic dehydration and the final equilibrium point in cereals and fruits [14]:

$$
\begin{gathered}
W F L=\frac{S_{1} t W F L_{\infty}}{1+s_{1} t} \\
S G=\frac{S_{2} t S G_{\infty}}{1+s_{2} t}
\end{gathered}
$$

In Equation (3a), WFL is the water lost by the foodstuff at time $t, s_{1}$ is a constant related to water loss and $W F L_{\infty}$ is the water lost at equilibrium. In Equation (3b), $S G$ is solids gained by the foodstuff at time $t, S_{2}$ is a constant related to solids gain and $S G_{\infty}$ is the amount of solids gained at equilibrium.

Finally, Peleg [17] developed an empirical model for sorption curves in the form of moisture vs time relationships of milk powder and rice, exposed to moist atmosphere or soaked in water. The model enabled prediction of moisture contents after long exposure from experimental data obtained in a relatively short time, i.e., before the moisture level appeared to reach a plateau. The model implied that the moisture equilibrium was somewhat higher than that determined on the assumption that the sample reached a constant weight, [17]-[23]:

$$
M(t)=M_{o}+\frac{t}{k_{1}+k_{2} t}
$$


where $M(t)$ is the moisture after time $t, M_{o}$ the initial moisture, and $k_{1,2}$ are constants.

In this paper, we try to use the expressions of the reported models applied to the data (moment of inertia) obtained by dynamic speckle technique.

Taking into account the above considerations, Equations (2)-(4) must be modified and turned into:

"NSC" Hawkes and Flink variable is set as the remaining water instead of adsorbed water, then Equation (2) could be stated as:

$$
N S C=N S C_{0}-K t^{0.5}
$$

where " $N S C_{0}$ ", represents the amount of initial water standardized.

So, in dynamic speckle technique we use the expression:

$$
I=I_{0}-K t^{0.5}
$$

where $I$ is the moment of inertia as a function of time, $I_{0}$ is the initial moment of inertia and $\left(I_{0}-I\right)$ represents the water remaining on the surface of the zeolite,

Azuara's et al. model equation became:

$$
I=I_{0}-\frac{s_{1} I_{\infty} t}{1+s_{1} t}
$$

where $\left(I_{0}-I_{\infty}\right)$ is the steady state moment of inertia.

Peleg's model equation became:

$$
I=I_{0}-\frac{t}{k_{1}+k_{2} t}
$$

where $I_{0}-\frac{1}{k_{2}}$ is the steady state moment of inertia and $\frac{1}{k_{1}}=\left(\frac{d I}{d t}\right)_{t=0}$ is the initial
variation of moment of inertia.

\section{Results and Discussion}

\subsection{Physicochemical Characterization}

Clinoptilolite used in this work is a heulandite-type, with chemical composition $(\mathrm{Na}, \mathrm{K})_{6}\left(\mathrm{Al}_{6} \mathrm{Si}_{30} \mathrm{O}_{72}\right) \cdot 20 \mathrm{H}_{2} \mathrm{O}$ previously reported [8] [24] [25]. Data are included in Table 1.

The framework topology of this mineral consists of a two dimensional pore system formed by 8-ring channels linking together [2]. This channels disposition allowed to zeolite has good adsorption properties for $\mathrm{CO}_{2}, \mathrm{SO}_{2}, \mathrm{NH}_{3}$ and $\mathrm{NO}_{x}$ gases [27] [28] [29] [30].

The cation exchange capacity (CEC) of this material has been previously determined and a value of $330 \mathrm{meq} / 100 \mathrm{~g}$ was found [28].

Chemical and physical properties of the zeolite can be modified with either inorganic basic or acid solutions. This fact mainly depends on the $\mathrm{Si} / \mathrm{Al}$ ratio.

The acid treatment conduces to the alumination process from the alumino-silicate structure removing $\mathrm{Al}^{3+}$-ions progressively. On the other hand, an increase of the temperature or alkalinity reduces the silica content, due to dehydration processes and $\mathrm{SiO}_{2}$ 
dissolution. This treatment also promotes the process of ion exchange cation $\left(\mathrm{Na}^{+}\right.$or $\mathrm{K}^{+}$)- $\mathrm{H}^{+}$. In basic treatment using, amoniacal solution, the silanol groups surface (hydroxyl) $\mathrm{SiO}_{2} \cdot \mathrm{OH}$, acquires a great concentration of $-\mathrm{OH}$ groups. Therefore, under this condition, the $\mathrm{NH}_{4}{ }^{+}$cations can be easily exchanged by other ions like $\mathrm{Na}^{+}$or $\mathrm{K}^{+}$. All these reactions produce chemical surface modifications that are evidenced by changes in the composition, in textural and structural properties, which could be analyzed by different physical-chemical analysis techniques.

Textural properties, surface area, volume and pores size, have been analyzed with nitrogen physic-sorption isotherms by BET model. The measure was carried out for pure and modified samples with acid, basic treatment included the two calcinated samples. The results found together with some SEM-EDS chemical data are reported in Table 2.

The values obtained are typical for natural zeolites, however a noticeable change for zeolite calcinated at $500^{\circ} \mathrm{C}$ was observed. In this case the $S_{\text {BET }}$ value was almost double and the pore size was lower than those the other samples.

Table 2 shows the composition of the minerals. It should be noted that the composition of the exchangeable cations, especially $\mathrm{Na}^{+}$for $\mathrm{Z}-\mathrm{H}^{+}$and $\mathrm{Z}-\mathrm{NH}_{4}{ }^{+}$is lower than that of the unmodified mineral.

Figure 3 shows the comparative X-Ray diffraction patterns. The Z-N pattern is in agreement with the PDF 79-1461 previously reported [8]. All samples show the similar patterns, indicating that the structure does not change with the different treatments. However, X-ray diffraction lines of the calcinated samples are slightly shifted to lower $2 \theta$ probably due to the increase of the cell volume. On the other hand, the X-ray diffraction lines of the $\mathrm{Z}-\mathrm{H}^{+}$and $\mathrm{Z}-\mathrm{NH}_{4}{ }^{+}$samples are slightly shifted to the higher $2 \theta$ suggesting a decrease of the volume cell in agreement with the low percentage of the $\mathrm{Na}^{+}$ (see Table 2).

Figure 4 shows the infrared spectra of the samples. The bands observed around 3600 $\mathrm{cm}^{-1}$ and $1600 \mathrm{~cm}^{-1}$ are assigned to stretching and bending modes of the water molecules. The bands located at $3424 \mathrm{~cm}^{-1}$ are associated with the stretching of -OH groups from water molecules coordinated to cationic species, which are interacting with the covalent network that leads to hydrogen bonds of different sizes. The bands between 1200 and $400 \mathrm{~cm}^{-1}$ are assigned to the stretching and bending modes of the T-O units $(\mathrm{T}=\mathrm{Si}$ or $\mathrm{Al})$ due to the [29] $\mathrm{TO}_{4}$ tetrahedral groups $\left(\mathrm{SiO}_{4}\right.$ and $\left.\mathrm{AlO}_{4}\right)$. The bands observed at 1206 and $607 \mathrm{~cm}^{-1}$ are assigned to the asymmetric and symmetric stretching

Table 2. Textural parameters by BET model and composition of $\mathrm{Na}, \mathrm{K}$ and $\mathrm{Si} / \mathrm{Al}$ by SEM-EDS for original clinoptilolite, modified and thermally treated forms.

\begin{tabular}{ccccccc}
\hline Sample & $\mathrm{S}_{\text {BET }}\left[\mathrm{m}^{2} / \mathrm{g}\right]$ & $\begin{array}{c}\text { Pore Vol. } \\
{\left[\mathrm{cm}^{3} / \mathrm{g}\right]}\end{array}$ & $\begin{array}{c}\text { Pore Size } \\
{[\AA]}\end{array}$ & $\mathrm{Na} \%$ & $\mathrm{~K} \%$ & $\mathrm{Si} / \mathrm{Al}$ \\
\hline $\mathrm{Z}-\mathrm{N}$ & $8.04[0.04]$ & 0.027 & 133.35 & $6.57[0.67]$ & $2.62[0.25]$ & 4.50 \\
$\mathrm{Z}^{+} \mathrm{H}^{+}$ & $6.80[0.03]$ & 0.021 & 123.09 & $2.20[0.19]$ & $2.47[0.90]$ & 5.33 \\
$\mathrm{Z}^{-N H_{4}}{ }^{+}$ & $8.76[0.06]$ & 0.027 & 122.08 & $1.70[0.36]$ & $1.08[0.02]$ & 5.70 \\
$\mathrm{Z}-250$ & $8.86[0.09]$ & 0.027 & 124.01 & $6.91[0.21]$ & $2.58[0.16]$ & 5.98 \\
$\mathrm{Z}-500$ & $12.80[0.03]$ & 0.028 & 88.46 & $6.94[0.29]$ & $2.36[0.46]$ & 6.38
\end{tabular}




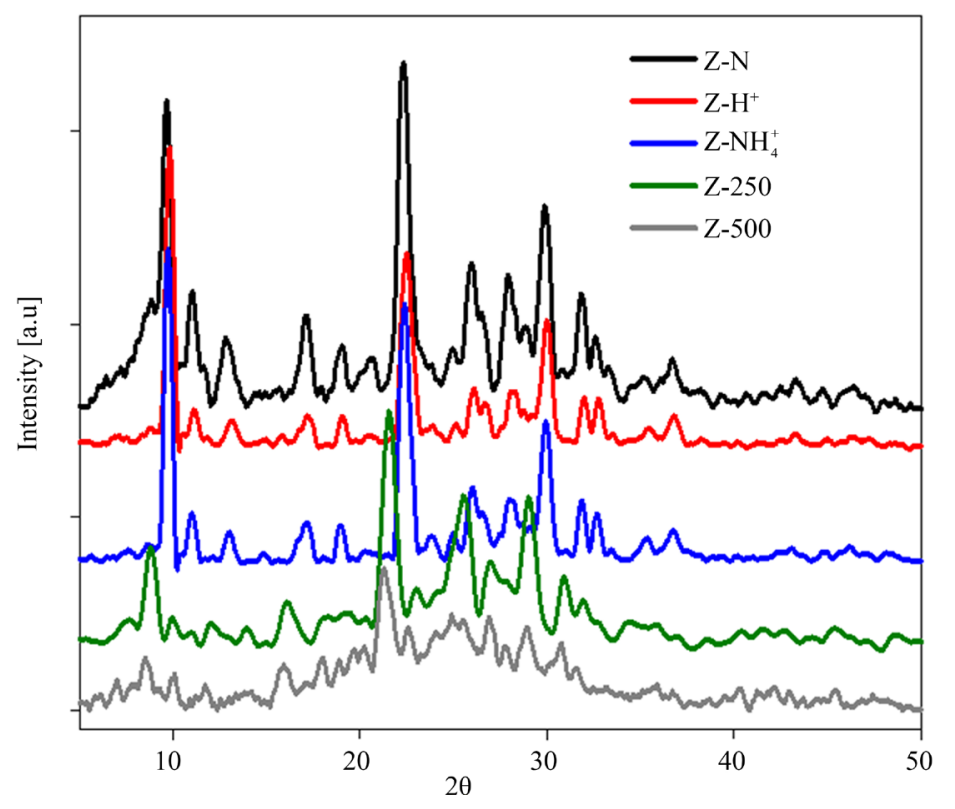

Figure 3. Comparative XRD patterns for pure Z-N and treated samples $\mathrm{Z}-\mathrm{H}^{+} ; \mathrm{Z}-\mathrm{NH}_{4}{ }^{+} ; \mathrm{Z}-250$ and Z-500.

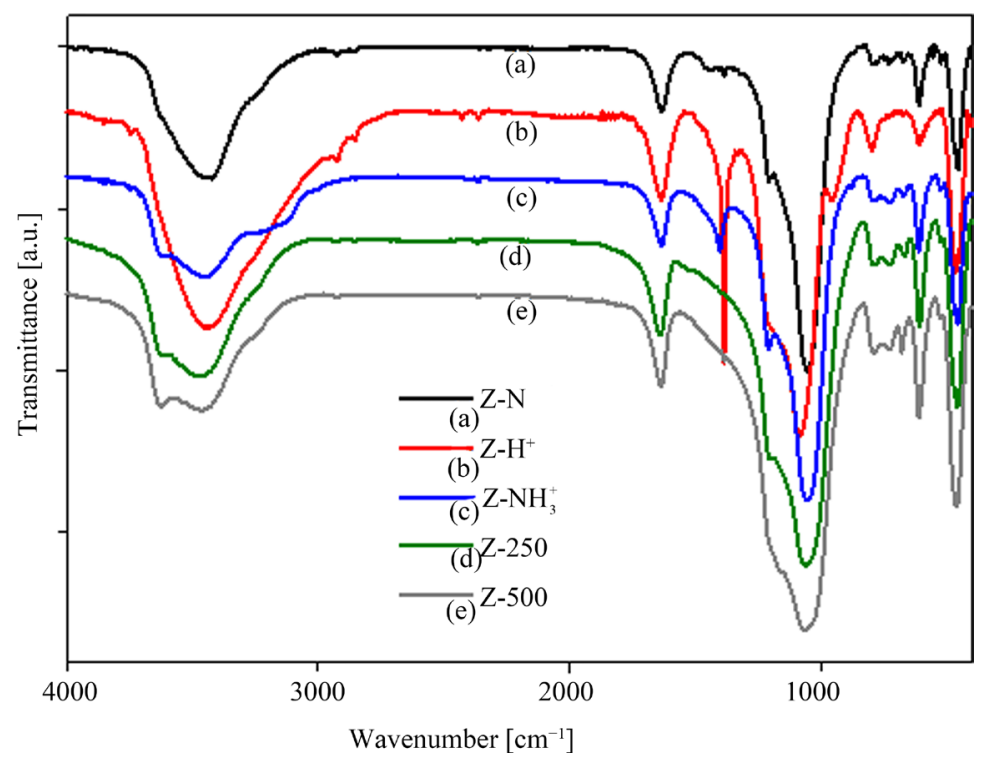

Figure 4. FTIR spectra of pure and modified samples of zeolite (range: 4000 to $400 \mathrm{~cm}^{-1}$ ).

modes of internal tetrahedral. The bands at 1053 and $794 \mathrm{~cm}^{-1}$ are associated with the asymmetric and symmetric stretching modes of external linkages [30], respectively.

The spectra of the acid form of the zeolite show that the external asymmetric mode $v_{\text {a }}$ T-O-T is lightly shifted to higher wave numbers respect to the natural zeolite. In this spectrum two new bands appear. One of them, located at $1384 \mathrm{~cm}^{-1}$ is attributed to asymmetric stretching modes of the $\mathrm{NO}_{3}$ bonds from the surface nitrate group which was generated by the $\mathrm{HNO}_{3}$ treating. The other one, observed at $955 \mathrm{~cm}^{-1}$ is assigned to Si-OH stretching mode of typical Brønsted acid site. 
The spectrum of $\mathrm{Z}-\mathrm{NH}_{4}{ }^{+}$shows in 3900 to $3200 \mathrm{~cm}^{-1}$ range, bands assigned to the $\mathrm{N}-\mathrm{H}$ stretching due to the presence of $\mathrm{NH}_{4}{ }^{+}$bonded to the surface. The band at 1632 $\mathrm{cm}^{-1}$ results from the superposition of the ammonium component and the mode corresponding to the bending vibrations of adsorbed $\mathrm{H}_{2} \mathrm{O}$. The presence of ammonium FTIR bands suggest the adduct formation between the ion and Brønsted acid sites of the zeolite [31] [32].

FTIR spectra of the samples do not show significant changes with the temperature in agreement with the X-ray diagrams. This fact is probably due to the high thermal stability of the structure [33] [34].

Table 3 shows the relevant bands and their tentatively assignment of the samples.

\subsection{DLS Technique Applied to the Hydro-Adsorption Analysis of Pure and Modified Zeolites}

Figure 5 shows the experimental data for original zeolite (Z-N) obtained with DLS technique (vs. time) (gray dots). Initial speckle activity decays monotonically to achieve stability in about 100 seconds.

Then, the experimental data were fitted using moment of inertia in Equations 6-8, and revealed the following values: a) Hawkes and Flink model [13]: $[k=-12.9375$, $I=155.3516, r^{2}=0.7900 \quad$ [Equation (6)], (short blue dashes), b) Azuara et al. model [14] $\left[I_{0}=2240, I_{\infty}=2260.2, s_{1}=3.614 \times 10^{6}, r^{2}=0.9157\right.$ ) [Equation (7)] and c) Peleg [17] $\left[I_{0}=2240, k_{1}=6.253 \times 10^{-4}, k_{2}=4.424 \times 10^{-4}, r^{2}=0.9157\right.$ ) [Equation (8)] were applied (long red dashes).

From Figure 5, it can be observed that the best fit is obtained with the Peleg's and Azuara's et al. models which fit the data with the same curve.

Table 3. Tentatively assignment of FTIR bands $\left(v \mathrm{~cm}^{-1}\right)$ for pure and modified samples of zeolite.

\begin{tabular}{|c|c|c|c|c|c|}
\hline $\begin{array}{l}\text { Tentatively } \\
\text { assignation }\end{array}$ & $\begin{array}{c}\text { Z-N } \\
\text { FTIR bands }\end{array}$ & $\begin{array}{l}{\mathrm{Z}-\mathrm{H}^{+}} \\
\text {FTIR bands }\end{array}$ & $\begin{array}{l}{\mathrm{Z}-\mathrm{NH}_{4}{ }^{+}} \\
\text {FTIR bands }\end{array}$ & $\begin{array}{l}\text { Z-250 } \\
\text { FTIR bands }\end{array}$ & $\begin{array}{l}\text { Z-500 } \\
\text { FTIR bands }\end{array}$ \\
\hline$v \mathrm{OH}$ & 3424 & 3436 & 3458 & 3469 & 3462 \\
\hline$v \mathrm{~N}-\mathrm{H}$ & & 3230 & 3240 & 3242 & \\
\hline$\delta \mathrm{H}_{2} \mathrm{O}$ & 1632 & 1633 & 1632 & 1639 & 1635 \\
\hline$\delta \mathrm{NO}_{3}$ & & 1384 & & & 1383 \\
\hline$\delta \mathrm{NH}_{4}$ & & & 1401 & & \\
\hline (a) $v_{\mathrm{a}} \mathrm{T}-\mathrm{O}-\mathrm{T}$ & 1206 & 1206 & 1207 & 1200 & 1158 \\
\hline (b) $v_{\mathrm{a}}^{\mathrm{T}} \mathrm{T}-\mathrm{O}-\mathrm{T}$ & 1053 & 1080 & 1053 & 1061 & 1062 \\
\hline$v_{\mathrm{s}} \mathrm{Si}-\mathrm{OH}$ & & 955 & & & \\
\hline (a) $v_{\mathrm{s}}^{\mathrm{T}} \mathrm{T}-\mathrm{O}-\mathrm{T}$ & 787 & 794 & 793 & 786 & 789 \\
\hline (b) $\nu_{\mathrm{s}} \mathrm{T}-\mathrm{O}-\mathrm{T}$ & 607 & 608 & 608 & 606 & 609 \\
\hline $\begin{array}{c}\text { Network modes } \\
\text { "ring } \\
\text { elongation" }\end{array}$ & 453 & 463 & 452 & 454 & 458 \\
\hline
\end{tabular}

Ref.: (a) External modes; (b) Internal modes. 


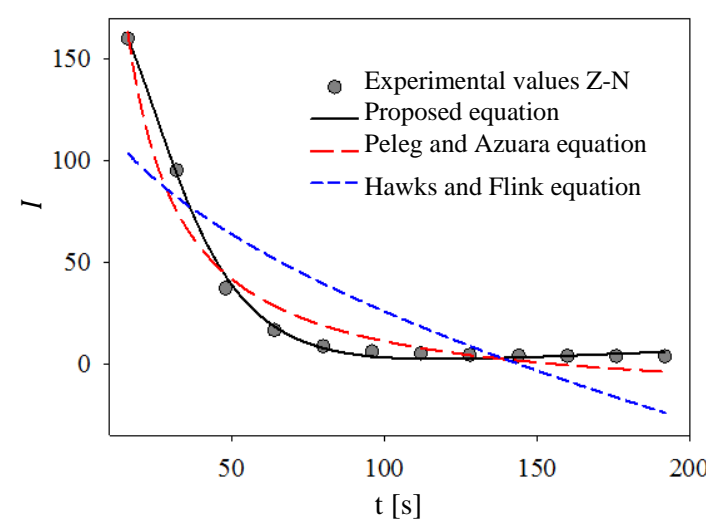

Figure 5. DLS activity experimental values for natural zeolite (gray dots); Hawkes and Flink, [Equation (6)] in short blue dashes and Peleg and Azuara et al., [Equation (7), Equation (8)], in long red dashes; proposed second order approach [Equation (9)] in black line.

These mathematical approaches are equivalent and produced the same results with the experimental trend but with a high error data. This effect is probably due to the zeolite containing micro and small mesopores, which produce greater water adsorption rate, so the first-order equation did not fit the experimental results. Then, we propose a new approach modifying the equation of Peleg, extending to the second order:

$$
I=I_{o}-\frac{t^{2}}{k_{0}+k_{1} t+k_{2} t^{2}}
$$

where $I_{0}=189.5, k_{0}=9.7874, k_{1}=-0.1656 \quad k_{2}=0.0060$, and $r^{2}=0.9987$.

Figure 5 shows that the fitting of the data is substantially improved with this approach. Also $r^{2}$ coefficient is close to one, showing that our approach is the best fit for the experimental data.

Taking into account the good fit for Z-N, the method was also applied for $\mathrm{Z}-\mathrm{H}^{+}$, $\mathrm{Z}-\mathrm{NH}_{4}{ }^{+}, \mathrm{Z}-250$ and Z-500 samples, in order to obtain the DLS activity (Figures 6 (a)-(d)). Data fitted to the experimental values are shown in Table 4.

Derivation of the Equation (9), the $I$ rate of change vs time was obtained. Figure 7 shows the curves for all samples.

The $I$ rate of change for the $\mathrm{Z}-\mathrm{N}$ is the highest comparing with the other samples. (see Figure 7 black line). It reaches a faster saturation adsorption at small times.

However, the behavior is different for the other samples, especially for those thermally treated where the rate of change at small times is slow and saturation occurs at larger times for high temperature (Z-500). This effect is probably due to the decrease in the average pore size (see Table 2) because external (adsorbed water) and internal (coordinated water) dehydration were produced by the calcination processes.

Therefore, the reversible process will require the formation of new hydrogen-bridges to achieve rehydration of the pores. This process will be slower than for unheated samples. In previous report [34], thermo-gravimetric analysis (TG) of clinoptilolites showed significant mass loss up to $500^{\circ} \mathrm{C}$, due to the loss of water coordinated to the intra-network ions $\left(\mathrm{Na}^{+}\right.$and $\left.\mathrm{K}^{+}\right)$. The complementary differential analysis (DT) 

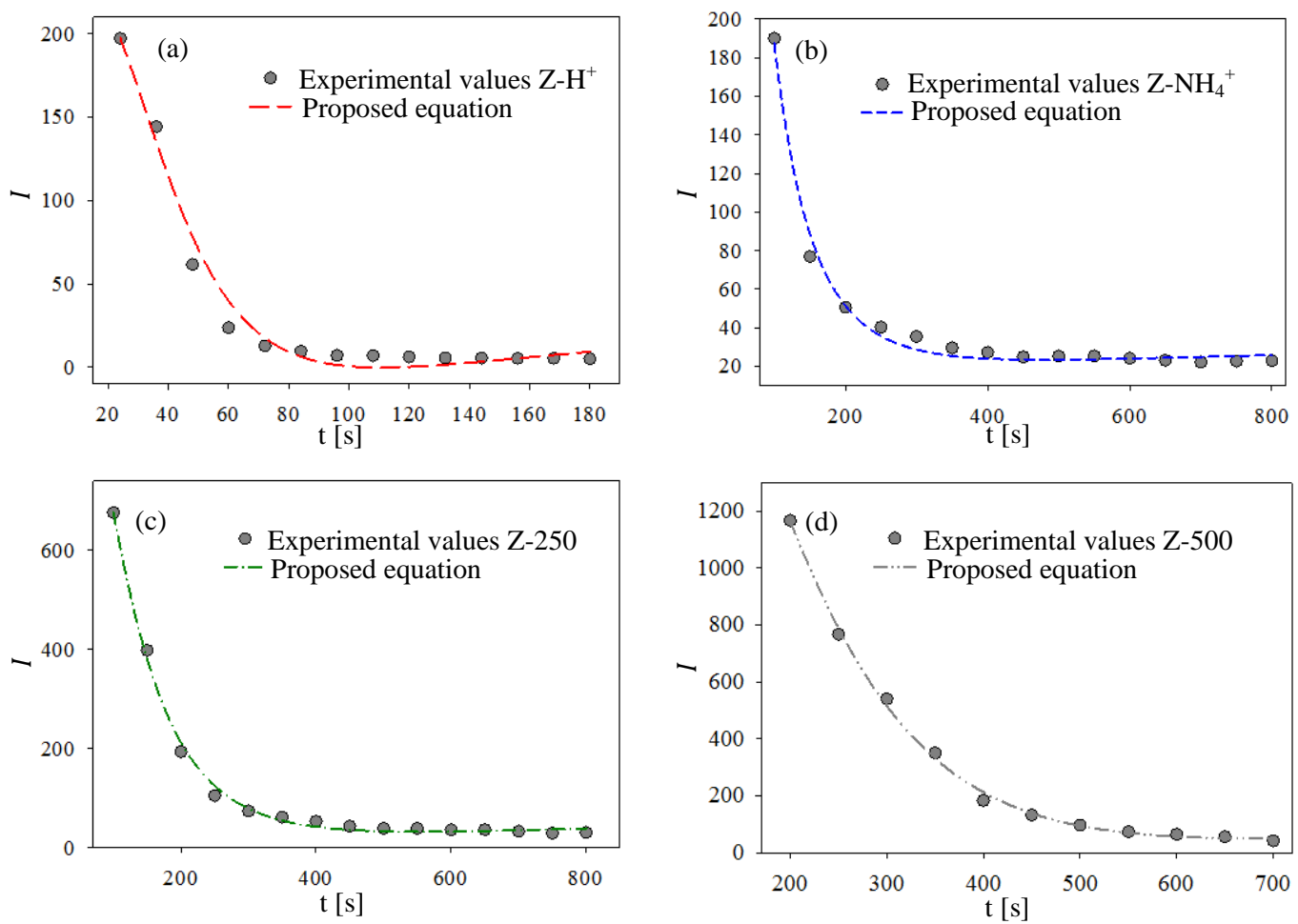

Figure 6. DLS activity for Z-H' $\mathrm{Z}^{+} \mathrm{NH}_{4}^{+} ; \mathrm{Z}-250$ and Z-500. Experimental values in gray dots and Equation (9) in dot line.

Table 4. Setting parameters for the moment of inertia (Equation (9)) for pure and modified zeolite.

\begin{tabular}{cccccc}
\hline Parameters & $\mathrm{Z}-\mathrm{N}$ & $\mathrm{Z}-\mathrm{H}^{+}$ & $\mathrm{Z}-\mathrm{NH}_{4}^{+}$ & $\mathrm{Z}-250$ & $\mathrm{Z}-500$ \\
\hline$\tau[\mathrm{s}]$ & 25.830 & 31.048 & 50.294 & 87.561 & 160.221 \\
$k_{0} I_{o}$ & 1854.71 & 3184.48 & 5296.48 & 17900.51 & 73447.81 \\
$k_{1} I_{o}$ & -31.2984 & -57.6000 & -22.1900 & -64.6454 & -219.3426 \\
$k_{2} I_{o}$ & 1.137 & 1.254 & 1.050 & 1.1061 & 1.2105 \\
$I_{o}$ & 189.5 & 700 & 2421 & 1229 & 256 \\
\hline
\end{tabular}

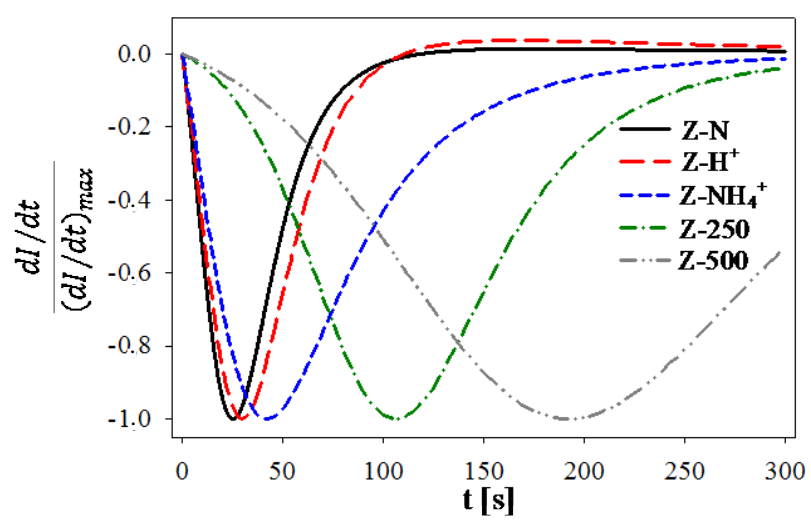

Figure 7. I rate of change vs. time for $\mathrm{Z}-\mathrm{H}^{+}$; $\mathrm{Z}-\mathrm{NH}_{4}{ }^{+}$; $\mathrm{Z}-250$ and $\mathrm{Z}-500$. 
revealed two endothermic peaks at 167 and $500^{\circ} \mathrm{C}$ [35]. This effect is in agreement with the existence of two different kinds of water molecules, adsorbed and coordinated molecules, respectively. For that reason it is expected that the rehydration process for the sample heated at $250^{\circ} \mathrm{C}$ will be faster than that at $500^{\circ} \mathrm{C}$.

Regarding acid and base modified samples, the $I$ rate of change behavior for $\mathrm{Z}-\mathrm{H}^{+}$ resulted similar to Z-N. However, this value is slightly higher for $\mathrm{Z}-\mathrm{NH}_{4}{ }^{+}$(Figure 7). This fact could be explained by the different sodium and potassium percentage (See Table 2), which resulted higher in the $\mathrm{Z}-\mathrm{H}^{+}$sample than in the $\mathrm{Z}-\mathrm{NH}_{4}{ }^{+}$one. $\mathrm{Na}^{+}$and $\mathrm{K}^{+}$ cations are the normal sites for the intra-network water adsorption and acidic zeolite resulted from the exchange of these cations by protonated ion species $\left(\mathrm{H}^{+}\right)$, giving rise to the formation of new hydrogen-bridges. This effect facilitates rehydration of $\mathrm{Z}-\mathrm{H}^{+}$ intra-network pores and a good hydro-adsorption capacity.

For $\mathrm{Z}-\mathrm{NH}_{4}{ }^{+}$, ammonium is also easily exchanged with $\mathrm{Na}^{+}$and $\mathrm{K}^{+}$ions, replacing the intra-network cations by " $\mathrm{NH}_{4} \mathrm{OH}$ " groups. This fact produces a steric effect in the pores and a slower rate of water molecules adsorption than the acid sites provided by $\mathrm{Z}-\mathrm{H}^{+}$. This behavior is consistent with an intermediate speckle activity for $\mathrm{Z}-\mathrm{NH}_{4}{ }^{+}$(See Figure 7).

\section{Conclusions}

The dynamic speckle technique was employed in the study of natural zeolites and their thermally and chemically modified forms. This technique has been used for the first time for Zeolites material and resulted a very useful tool to compare the hydro-adsorption properties in different treatment Zeolites sample.

According the water adsorption process of the samples, the experimental results show the temporary evolution of the speckle patterns. The parameters of the optical configuration used to produce speckle have been fitted using an improved Peleg's equation.

The good agreement between the experimental DLS results and calculated values can be considered as a potential low cost, non-destructive and simple method to study different materials of interest such as adsorbents or catalysts supports.

\section{Acknowledgements}

We are grateful to Lic. Mariela Theiler, Mrs. Graciela Valle and Eng. Edgardo Soto for their technical assistance.

The authors would like to thank the following institutions for funding this work:

CONICET (PIP 0003, 0771); CICPBA (Project 832/14) and Universidad Nacional de La Plata (Projects X606 and I172).

\section{References}

[1] Inglezakis, V.J., Stylianou, V.J. and Loizidou, M. (2010) Ion Exchange and Adsorption Equilibrium Studies on Clinoptilolite, Bentonite and Vermiculite. The Journal of Physical Chemistry A, 71, 279-284. https://doi.org/10.1016/j.jpcs.2009.12.077

[2] Rivera, A. and Farias, T. (2005) Clinoptilolite-Surfactant Composites as Drug Support: A New Potential Application. Microporous and Mesoprous Materials, 80, 337-346. 
https://doi.org/10.1016/j.micromeso.2005.01.011

[3] Panagiotis, M. (2011) Application of Natural Zeolites in Environmental Remediation: A Short Review. Microporous and Mesoporous Materials, 144, 15-18.

[4] Palevic, K., Subotic, B. and Colic, M. (2001) Biomedical Applications of Zeolites. Zeolites and Mesoporous Materials at the Dawn of the 21st Century. In: Galarneau, A., Di Renzo, F., Fagula, F. and Vedrine, J., Eds., Studies in Surface Science and Catalysis 135, 32-O-01, 170.

[5] Araya, A. and Dyer, A. (1981) Studies on Natural Clinoptilolites. Journal of Inorganic and Nuclear Chemistry, 43, 589. https://doi.org/10.1016/0022-1902(81)80508-8

[6] Breck, D.W.J. (1964) Crystalline Molecular Sieves: Report of the New England Association of Chemistry Teachers. Journal of Chemical Education, 41, 678. https://doi.org/10.1021/ed041p678

[7] Minato, H. (1968) Characteristics and Uses of Natural Zeolites. Koatsugasu, 5, 536-547.

[8] Agosto, M.F. (2012) Estudio de zeolitas procedentes de depósitos Argentinos. Aspectos tecnológicos que posibiliten su aplicación en agroindustria y control ambiental. Ph.D. Dissertation, National University of La Plata Argentine, La Plata.

http://hdl.handle.net/10915/26009

[9] Oulamara, A., Tribillon, G. and Dubernoy, J. (1989) Biological Activity Measurement on Botanical Specimen Surfaces Using a Temporal Decorrelation Effect of Laser Speckle. Journal of Modern Optics, 36, 165-179. https://doi.org/10.1080/09500348914550221

[10] Rabal H. and Braga R., Eds. (2009) Dynamic Laser Speckle and Applications. CRC Press, Boca Ratón.

[11] Cabello, C.I., Bertolini, G., Amaya, S., Arizaga, R. and Trivi, M. (2008) Hydrophilic Character Study of Silica-Gel by a Laser Dynamic Speckle Method. Revista Cubana de Física, 25, 67-69.

[12] Cabello, C.I., Bertolini, G., González, M.J., Botto, I.L., Arizaga, R. and Trivi, M. (2011) Materials Adsorption Characterization by Random Coherent Electromagnetic Waves. Proceedings PIERS Progress in Electromagnetics Research Symposium, Marrakesh, 20-23 March 2011, 499-501. www.piers.org

[13] Hawkes, J. and Flink, J.M. (1978) Osmotic Concentration of Fruit Slices Prior to Freeze Dehydration. Journal of Food Processing and Preservation, 2, 265-284. https://doi.org/10.1111/j.1745-4549.1978.tb00562.x

[14] Beristain, C.I., Azuara, E., Garcia, H.S. and Vernon-Carter, E.J. (1996) Kinetic Model for Water/Oil Absorption of Mesquite Gum (Prosopis juliflora) and Gum Arabic (Acacia senegal). International Journal of Food Science and Technology, 31, 379-386. https://doi.org/10.1046/j.1365-2621.1996.00353.x

[15] Azuara, E., Beristain, C.I. and Gutiérrez, G.F. (1998) A Method for Continuous Kinetic Evaluation of Osmotic Dehydration. Lebensmittel-Wissenschaft \& Technologie, 31, 317321. https://doi.org/10.1006/fstl.1997.0364

[16] Azuara, E., Cortes, R., Garcia, H.S. and Beristain, C.I. (1992) Kinetic Model for Osmotic Dehydration and Its Relationship with Fick's Second Law. International Journal of Food Science and Technology, 27, 409-418. https://doi.org/10.1111/j.1365-2621.1992.tb01206.x

[17] Peleg, M. (1988) An Empirical Model for the Description of Moisture Sorption Curves. Journal of Food Science, 53, 1216-1217. https://doi.org/10.1111/j.1365-2621.1988.tb13565.x

[18] Agu, H.O., Badau, M.H. and Abubakar, U.M. (2013) Modeling the Water Absorption Characteristics of Various Local Pearl Millet Grains and Hungry Rice (Digitaria exilis) during Soaking Using Peleg's Equation. Focusing on Modern Food Industry, 2, 161-169.

[19] Masoumi, A.A., Shafaei, S.M. and Roshan, H. (2016) Analysis of Water Absorption of Bean 
and Chickpea during Soaking Using Peleg Model. Journal of the Saudi Society of Agricultural Sciences, 15, 135-144. https://doi.org/10.1016/j.jssas.2014.08.003

[20] Turhan, M., Sayar, S. and Gunasekaran, S. (2002) Application of Peleg Model to Study Water Absorption in Chickpea during Soaking. Journal of Food Engineering, 53, 153-159. https://doi.org/10.1016/S0260-8774(01)00152-2

[21] Vengaiah, P.C., Raigar, R.K., Srivastav, P.P. and Majumdar, G.C. (2012) Hydration Characteristics of Wheat Grain. CIGR International Journal of Agricultural Engineering, 14, 116119.

[22] Kashiri, M., Kashaninejad, M. and Aghajani, N. (2010) Modeling Water Absorption of Sorghum during Soaking. Latin American Applied Research, 40, 383-388.

[23] Sopade, P.A., Ajisegiri, E.S. and Badau, M.H. (1992) The Use of Peleg's Equation to Model Water Absorption in Some Cereal Grains during Soaking. Journal of Food Engineering, 15, 269-283. https://doi.org/10.1016/0260-8774(92)90010-4

[24] Botto, I.L., Canafoglia, M.E., Lick, I.D., Cabello, C.I., Schalamuk, I.B., Minelli, G. and Ferraris, G. (2004) Environmental Application of Natural Microporous Aluminosilicates: $\mathrm{NO}_{x}$ Reduction by Propane over Modified Clinoptilolite Zeolite. Journal of the Argentine Chemical Society, 92, 139-153.

[25] Agosto, F., Canafoglia, M.E., De Barrio, R., Cabello, C.I., Schalamuk, I., Minelli, G. and Botto, I.L. (2005) Depósitos tobaceos terciarios zeolitizados del Área de Paganzo (Provincia de La Rioja). Su potencialidad tecnológica. Proceedings of 16th Congreso geológico Argentino, 16, 847-854.

[26] Anderson, J.R. and Pratt, K.C. (1985) Introduction to Characterization and Testing of Catalysts. Academic Press, Sydney.

[27] Mortier, W.J. and Pearce, J.R. (1981) Thermal Stability of the Heulandite-Type Frame Work; Crystal Structure of the Calcium/Ammonium Form Dehydrated at $483 \mathrm{~K}$. American Mineralogist, 66, 309-314.

[28] Colella, C. (1996) Ion Exchange Equilibria in Zeolite Minerals. Mineralium Deposita, 31, 554-562. https://doi.org/10.1007/BF00196136

[29] Van Bekkum, H., Flanigen, E.M., Jacobs, P.A. and Jensen, J.C. (2001) Introduction to Zeolite Science and Practice. Studies in Surface Science and Catalysis Vol. 137, 345 p.

[30] Karge, H.G. (1998) Characterization by Infrared Spectroscopy. Microporous and Mesporous Materials, 22, 547-549. https://doi.org/10.1016/S1387-1811(98)80021-8

[31] Tomazovic, B., Ceranic, T. and Sijaric, G. (1996) The Properties of the NH4-Clinoptilolite. Part 1. Zeolites, 16, 301-308. https://doi.org/10.1016/0144-2449(95)00118-2

[32] Tomazovic, B., Ceranic, T. and Sijaric, G. (1996) The Properties of the NH4-Clinoptilolite. Part 2. Zeolites, 16, 309-312. https://doi.org/10.1016/0144-2449(95)00117-4

[33] Sakizci, M., Alver, B.E. and Yörükoğullari, E. (2011) Thermal and $\mathrm{SO}_{2}$ Adsorption Properties of Some Clays from Turkey. Journal of Thermal Analysis and Calorimetry, 103, 435441. https://doi.org/10.1007/s10973-010-0928-0

[34] Alver, B., Sakizci, M. and Yörükoğullari, E. (2010) Investigation of Clinoptilolite Rich Natural Zeolites from Turkey: A Combined XRF, TG/DTG, DTA and DSC Study. Journal of Thermal Analysis and Calorimetry, 100, 19-26. https://doi.org/10.1007/s10973-009-0118-0

[35] Barrer, R.M. and Murphy, E.V.T. (1970) Influence of de Cationation and de Alumination on Sorption by Mordenite and Clinoptilolite. Journal of the Chemical Society A, 25062514. https://doi.org/10.1039/j19700002506 